\title{
Meeting Users Where They Are
}

Delivering Dynamic Content and Services through a Campus Portal

Graham Sherriff, Dan DeSanto, Daisy Benson, and Gary S. Atwood

\section{ABSTRACT}

Campus portals are one of the most visible and frequently used online spaces for students, offering one-stop access to key services for learning and academic self-management. This case study reports how instruction librarians at the University of Vermont collaborated with portal developers in the registrar's office to develop high-impact, point-of-need content for a dedicated "Library" page. This content was then created in LibGuides and published using the Application Programming Interfaces (APIs) for LibGuides boxes. Initial usage data and analytics show that traffic to the libraries' portal page has been substantially and consistently higher than expected. The next phase for the project will be the creation of customized library content that is responsive to the student's user profile.

\section{INTRODUCTION}

For many academic institutions, campus portals (also referred to as enterprise portals) are one of students' most frequently used means of interacting with their institutions. Campus portals are websites that provide students and other campus constituents with a "one-stop shop" experience, with easy access to a selection of key services for learning and academic self-management.

Typically, portals provide features that make it possible for students to obtain course information, manage course enrollment, view grades, manage financial accounts, and access information about campus activities. For faculty and staff, campus portals provide access to administrative resources related to teaching, human relations, and more. These campus portals are different from library portals, which some libraries implemented in the 2000s as a way to centralize access to key library services. ${ }^{1}$

Currently, the public-facing websites of many colleges and universities serve a crucial role in marketing the institution to prospective students. This creates an incentive to be as comprehensive as possible and to showcase the full breadth of programs, services, offices, and facilities. A common disadvantage to this approach to institutional web design is information overload: an overwhelming array of labels and links that diminish the ability of current affiliates to find and access the services they need. These sites are designed for external users for whom the research and educational functions of the library are a low priority.

Campus portals, however, are designed for internal users and can take a more selective approach. They give student and faculty users a view of campus services that aligns with their priorities and places them in a convenient interface. In this sense, they are tools for information management. Campus portals play a critical role in students' daily lives because they do much more than simply present information. Carden observes that campus portals have these key characteristics:

Graham Sherriff (graham.sherriff@uvm.edu) is Instructional Design Librarian, University of Vermont. Dan DeSanto (ddesanto@uvm.edu) is Instruction Librarian, University of Vermont. Daisy Benson (daisy.benson@uvm.edu) is Library Instruction Coordinator, University of Vermont. Gary S. Atwood (gatwood@uvm.edu) is Education Librarian, University of Vermont. 
- allow a single user authentication and authorization step at the initial point of contact to be applied to all (or most) other entities within the portal;

- allow multiple types and sources of information to be displayed on a single composite screen (multiple "channels");

- provide automated personalization of the selection of channels offered, based on each user's characteristics, on the groups to which each user belongs, and possibly on the way in which the system has historically been used;

- allow user personalization of the selection of channels displayed and the look-and-feel of the interface, based on personal preferences;

- provide a consistent style of access to diverse information sources, including "revealing" legacy applications through a new consistent interface; and

- facilitate transaction processing as well as simple data access. ${ }^{2}$

In sum, enterprise portals use a combination of advanced technologies that have the ability to present both static and user-responsive information in a space reserved for affiliates of the university.

These abilities present an attractive venue for libraries to leverage the capabilities of a campus portal to present users with dynamic, personalized instructional experiences - in a space where users are. This aligns with the principles of user-centered design, which emphasizes the need to empathize with users' needs and perspectives. Simplicity, efficiency, convenience, and responsiveness to each user's individual circumstances are critical. ${ }^{3}$

The idea of presenting libraries' content through a campus portal is not a new one. Stoffel and Cunningham surveyed libraries in 2004 and, while finding that "library participation in campus portals is ... relatively rare," of the sixteen self-selected responding campuses, ten had a library tab or a dedicated library channel within their campus portal, while two more had a channel or tab under development. ${ }^{4}$ The types of library integration described in most examples consisted of using the portal's campus authentication to link to a user's library account and view borrowed books, fines, holds, and announcements. While resources like federated searches, research guides, and lists of journals and databases appeared in some respondents' portals, they largely appeared as static content rather than responding to the user's profile. Since 2004, portals have remained a core part of the University of Vermont's information delivery system, but portal integration remains relatively rare among libraries and most have done little to integrate new tools such as research guides or develop instructional content that leverages a portal's user-responsive design.

As a result, there is little in the literature on libraries' integration of content into campus portals, but a small number of case studies provide proof of concept, such as Lehigh University, California State University-Sacramento, and Arizona State University. ${ }^{5}$ These case studies also illustrate the importance of cross-campus collaboration. Our project required some critical elements, specifically access to the campus portal and a method for publishing content. The projects described in the case studies were successful partly because they were able to apply advanced programming expertise that was not available to our group, such as API coding. Instead, our group was able to obtain these critical inputs through a partnership with the University of Vermont registrar's office. 
At the University of Vermont, the campus portal uses the Banner product licensed from Ellucian and has branded it as "MyUVM." It is administered by the registrar's office. Librarians have observed that it is central to students' academic lives. Students go to MyUVM as their pathway to many of the online services and tools that they use. They go there to check email, log in to the learning management system (LMS), check grades, to add, drop, or withdraw from courses, to check their schedule, and more. They go there to carry out tasks.

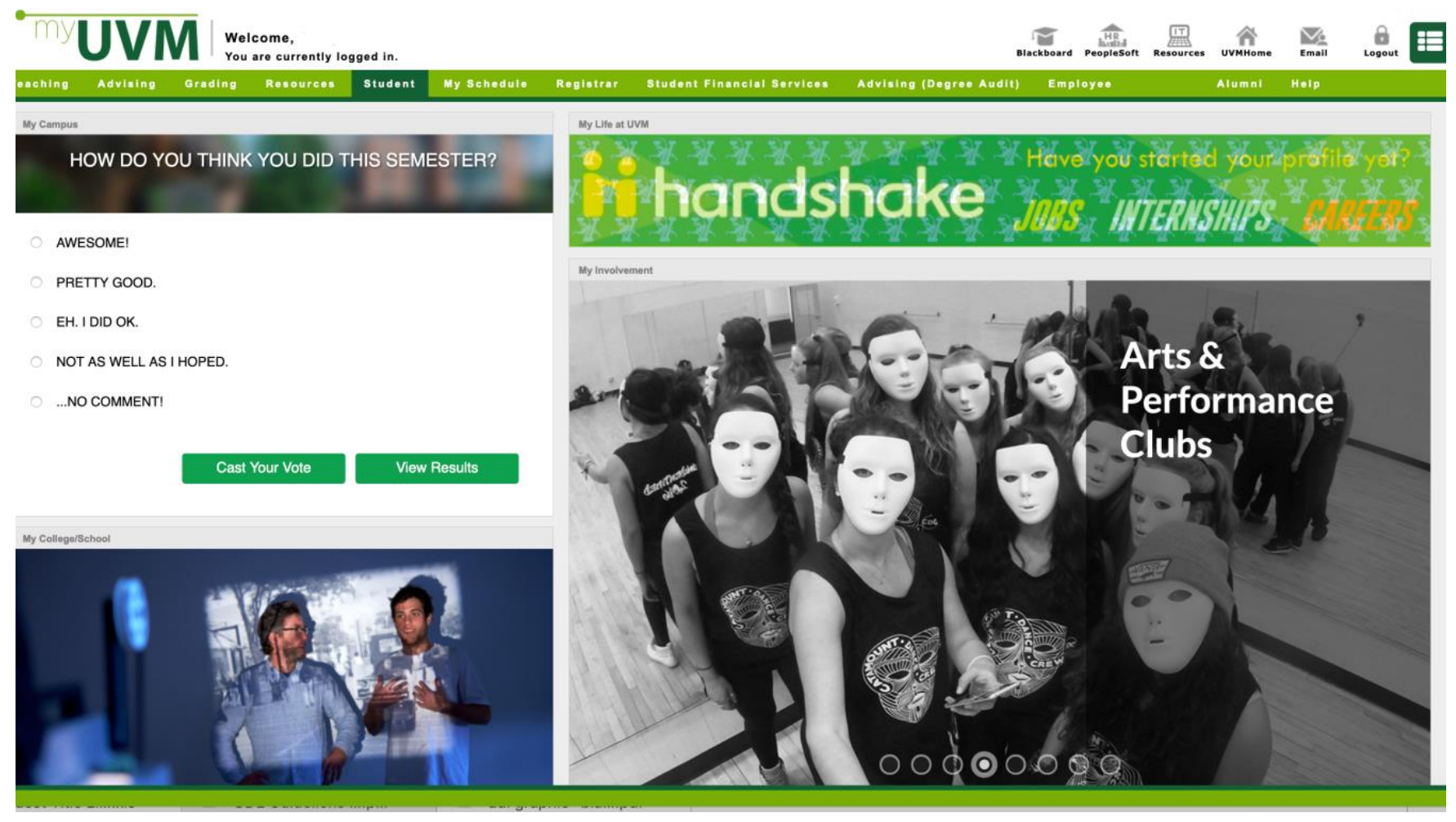

Figure 1. Screenshot of MyUVM (https://myuvm.uvm.edu as it was on March 1, 2019).

The importance of MyUVM is communicated to University of Vermont students at orientation. In this way, first-year students learn at the earliest point, even before their academic programs begin, that the portal is their primary gateway for access to campus academic services. This shapes their view of the services available to them and how those services are organized. It also shapes how they reach those services and how they interact with them. At the same time, the selective principle underlying the campus portal means that if something is not present, it is less visible and less accessible, and there is a risk of signaling to students that it is not important to their daily lives or their academic performance.

\section{METHODS}

The characteristics of campus portals and their contents motivated instruction librarians to explore the possibility of integrating library services into MyUVM. In 2014, the University of Vermont Libraries' Educational Services Working Group-a small cross-libraries group of librarians who work on a variety of projects supporting classroom instruction and research assistance-began by defining the desirable scope of possible portal content. 
The Educational Services Working Group quickly determined that library content included in the portal should be designed to conform with the principle of priority-based selectivity employed across the portal as a whole. This content should not attempt to represent the full suite of library information and services available. This would replicate the websites of the three libraries on campus and would risk creating overload and disorientation, in a similar way to institutional websites. It is common for actionable and instructional material to become buried beneath links on a library homepage, and the homepages of our three libraries' websites are no different. Our hope was to reposition selected instructional content such as research guides, databases-bysubject, chat reference, and liaison librarian contacts in a venue with which students are used to interacting.

The goal of the project was the strategic positioning of dynamic, responsive information about research services in a venue with which students frequently interact. Research librarians would select and organize the most important and pertinent instructional content. Such selectivity fit well within the portal's principle for curating content: high-use tools and services that directly support students' priorities.

Thus the objective for this project would not be the re-creation of the library websites within MyUVM. It was also determined that the scope would exclude content that might be considered marketing or engagement for its own sake, for the same purpose of minimizing users' cognitive load and helping them to quickly find the features they need.

The MyUVM developers in the registrar's office were enthusiastic about working with us on this project, which partly reflects an increased attention across campus to equitable access to student services for all users-something that is important for its own sake, but also for the purposes of accreditation. Following preliminary discussions in early 2018, MyUVM developers created a test "Libraries" page, equivalent to a full screen of content, and assigned to our group the privileges necessary to view it in the MyUVM test environment. Each page in MyUVM is composed of a series of content boxes or channels. In developing our new page, our task was to develop content for the desired channels.

We began our process for composing the page with a card-sorting exercise that identified priorities for the content that should be highlighted. The participants were the group's members, in order to expedite initial decisions about content that could be tested with users at a later point in the project.

Items that figured prominently in this process were the libraries' "Ask a Librarian" service, research guides, and search tools (discovery layer, databases, and journal directory). This confirmed that our group's priorities centered on users' transactional interactions with library services and not merely the one-way promotion of library information.

The results of the card sorting were then translated into a wireframe (see figure 2). Each square in the wireframe represented a channel for which we would need to create the appropriate content:

- Ask a Librarian (contact details for the libraries' research assistance services)

- Research Guides (subject and class guides)

- Search our Collections (search tools for the discovery layer, databases, and journal directory) 
- Research Roadmap (the libraries' suite of tutorials on foundational research skills)

- Featured Content (a channel for rotating or temporary time-specific content)

- Libraries (a box with a link to each of the three libraries on campus; we later added a channel for each library)

- The wireframe also envisaged the inclusion of a pop-out chat widget.

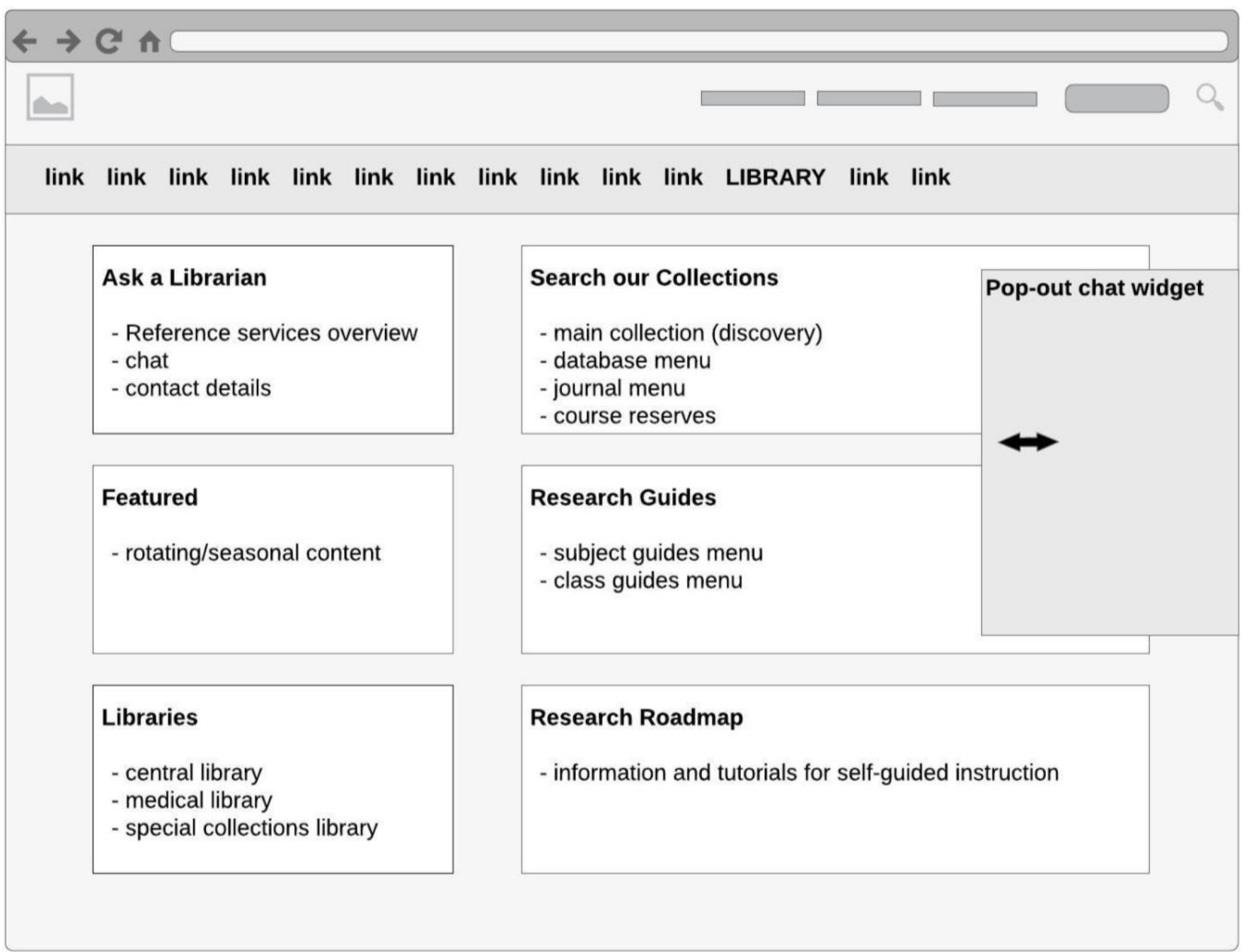

Figure 2. Wireframe for library content.

As noted, the project needed a process that would enable our group to create and publish this content autonomously, but without requiring advanced programming skills on our part. We learned that MyUVM is capable of publishing content pushed from a webpage by using its URL. This meant that we could create content in LibGuides, a platform with which our group was very familiar, and then push the content of an individual LibGuide box to a MyUVM channel simply by providing the LibGuide box URLs to the portal developers.

This method offers several advantages. Importantly, it meant that our group had direct control of the box content and was able to publish it without needing the MyUVM developers to review and authorize every edit. 
Those involved in this project faced important decisions early in the process regarding which resources we deemed essential for inclusion and best suited to this new online context. Once items were selected, it was important to keep user behaviors in mind as we prioritized "above the fold" content. Students are used to quickly popping into the portal, finding what they need, and popping out. We tried to place interactive content that fit this use pattern in high-visibility places and moved content that required more sustained reading and attention further down the page. A challenge faced during the design process was our campus's lack of a unified, cross-libraries web presence. The three libraries on our campus have separate websites, but the University of Vermont portal required that we present a unified "Libraries" presence. In some cases, such as links back to library webpages, we were easily able to treat the three libraries separately. In other cases, such as our research guides, we were able to merge resources from multiple libraries. In still other cases, such as our chat widgets, we had to make decisions about which library's resource would be featured and which other versions would be secondary.

The prototyping and testing phases revealed that some content needed to be adjusted in order to display in MyUVM as desired. LibGuides' tabbed boxes and gallery boxes did not display correctly. Also, some style coding inherited from the LibGuides boxes needed to be adjusted in order to display cleanly. One item, "Course Reserves," was present in the wireframe but not the page at the time of implementation. We continue to work on the development of a widget for searching "Course Reserves" holdings. The version of the "Library" page at the time of going live is shown in figure 3.

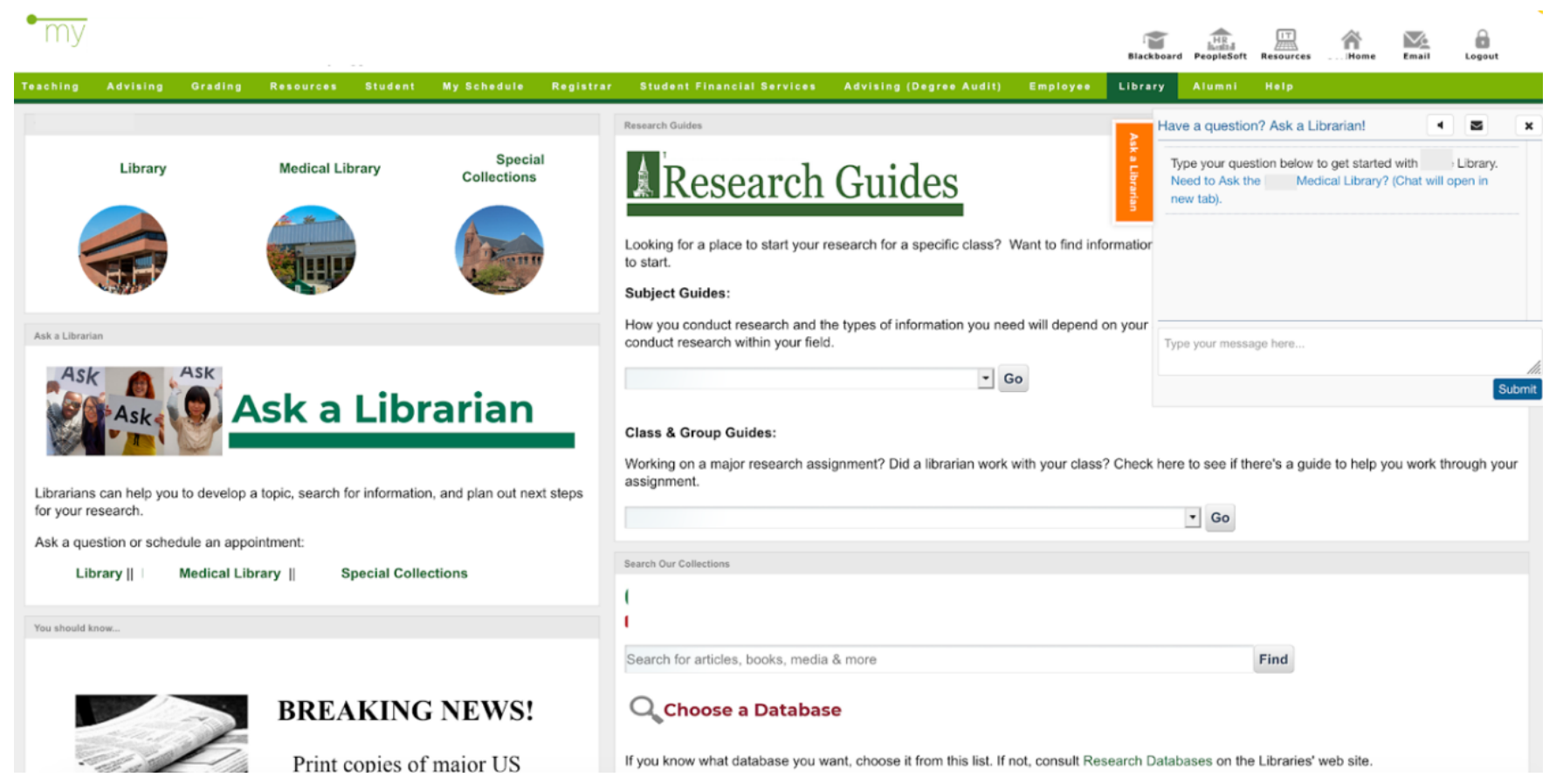

Figure 3. Screenshot of the "Library" page in MyUVM.

The "Research Guides" channel has a dropdown menu for subject guides and another for class guides. These menus were created using LibGuides widgets, meaning that they update automatically as guides are published and unpublished, and do not require any manual maintenance. 
The "Search Our Collections" channel includes three access points to the libraries' collections. This contrasts with the libraries' websites, which display only the discovery layer search box. The latter approach has the advantage of promoting one-stop searching, but also the disadvantage of overwhelming users with non-relevant results.

Channels on the left side of the page are less dynamic and interactive. At the top, links to the three libraries on campus provide highly visible quick access for students looking for the libraries' websites. Similarly, the "Ask a Librarian" channel quickly gets students to reference and consultation services at their home library. The "You Should Know" channel provides a space for rotating content to be changed based on time-of-year, events on campus, or other perceived student needs.

\section{RESULTS}

The "Library" page in MyUVM went live in January 2019, at the same time that spring semester classes began. Our preliminary review of results from the semester, based on data collected from MyUVM, LibGuides Statistics, and Google Analytics, has identified several positive outcomes.

MyUVM data showed that there were 18,891 visits to the "Library" page during the period from mid-January to the end of March, a period of eleven weeks when classes were in session. This volume of traffic substantially exceeded our group's expectations for the first months following implementation, during a period when we were only beginning to promote awareness of the page.

Data also showed that usage during this period was generally consistent. The most significant variation in traffic was a small peak in late February that corresponded with a high point in the level of library instruction.

LibGuides Statistics showed an overall increase in usage of subject guides, though it is not possible to attribute this to the MyUVM project with complete certainty. In addition, however, we also observed that for many of our guides during this period, MyUVM was among the top referring sites.

LibGuides Statistics also recorded unexpectedly large increases in usage for the "Research Roadmap" that we attribute primarily to the MyUVM project. Four sections of the "Research Roadmap" experienced increases of more than 100 percent during the January-March period. The Research Roadmap's “More Help" page showed a 65 percent drop in visits, but a possible explanation for this is that the highlighting of sections in MyUVM is providing more-immediate help to our users in finding what they need and promoting independent use of instructional materials by students.

LibChat Statistics indicated a significant increase in chat reference transactions at Howe Library, the University of Vermont's central library: a 23 percent increase over the count for the fall 2018 semester, with the implementation of the MyUVM project being the only reasonable explanation.

All initial data appear to show that users are finding and continuing to use the "Library" tab in the portal. They are discovering guides and using the embedded chat widget. We plan to gather more usage data for other channels on the page to better inform our picture of what users are doing once they find and view the "Library" tab. As campus portals have become a ubiquitous part of university life, revisiting the library's role in these portals seems worthwhile, especially given that 
commonplace design tools like LibGuides dramatically lower the technological acumen needed for creating content.

\section{FUTURE DIRECTIONS}

The next step for this project is to leverage the ability of a campus portal to create a MyUVM homepage library channel that customizes the display of content, based on unique user characteristics. When the user logs in, they are routed to the portal's landing page, which is dynamically created based upon their student or faculty status, enrollment in a college or school, level of study (graduate/undergraduate), or number of years attending the University of Vermont. This page has the ability to conform to the user in even more granular ways and dynamically display content based upon their major or other demographic categories such as study abroad status, veteran status, or first-year students.

By leveraging the portal's ability to display user-specific content, the University of Vermont Libraries have the ability to customize instructional content tailored to a user's information needs and place that content in a channel that will display alongside other channels on the MyUVM homepage. A first-year history major's library channel could contain tutorials on working with primary sources, a link to their liaison librarian, links to digitized newspaper collection, and help guides for Chicago citation style. A graduate student in nursing might see information about evidence-based practices for developing a clinical question, help guides for using PubMed and CINAHL, and resources for point-of-care. A faculty member in psychology might find tutorials for creating alerts in their favorite journals, information about copyright and reserves material, or information about citation-management software. In each case, the portal pushes resources and assistance to each user that best fits their specific need, as informed by the librarians best equipped to address that need.

This last step of placing dynamic content on the MyUVM homepage will require a great deal of coordination with liaison librarians both to identify the most pertinent disciplinary information to place in the portal and to identify the times of year when certain information is most relevant. To keep portal content dynamic and pertinent to users, a system will need to be created for releasing and removing content on a regular basis and this scheduling of content will require the input of liaison librarians. The Educational Services Working Group will need to manage this scheduling, as well as the enforcement of portal design conventions in coordination with the MyUVM developers. Although this management may end up being complex, it is not insurmountable, and our next steps will be to both to create a system for content creation and management, and to begin to create test content for a sample of user groups.

We also plan to gather more data and expand our analytics capabilities to assess how users are using content on the MyUVM "Library" page and examine which features are most popular, how much traffic is being driven back to our websites, and how users are interacting with the features on the page.

\section{CONCLUSION}

Our project has confirmed our initial inclination that students go to MyUVM as a finding tool for finding inter-campus resources. Also, faculty have reported accessing library resources through the portal and directing their students to that pathway as well. The immediate high use and consistency of use indicate that we have placed our selected Libraries resources in a high-traffic 
venue. Instead of attempting to coax students to our web outpost in the wilds of the internet, we have placed an exit ramp from a highway they already travel. This has proven overwhelmingly effective and confirms, on our campus at least, the literature from the mid-2000s pointing out the opportunity created for libraries by campuses' institutional adoption of portal systems.

In all, the project has been a worthwhile venture for the University of Vermont Libraries. We have observed immediate use and better-than-expected levels of traffic, as well as continued use throughout the semester. It appears that once students wear a path to resources in MyUVM, they are continuing to use that path as a way to access library content. We look forward to further customizing that content in the near future.

\section{ACKNOWLEDGEMENTS}

We gratefully acknowledge David Alles, Portal Developer, and Naima Dennis, Senior Assistant Registrar for Technology, in the University of Vermont Office of the Registrar, for their contributions to the design and development of this project.

\section{ENDNOTES}

${ }^{1}$ Scott Garrison, Anne Prestamo, and Juan Carlos Rodriguez, "Putting Library Discovery Where Users Are," in Planning and Implementing Resource Discovery Tools in Academic Libraries, ed. Mary Pagliero Popp and Diane Dallis (Hershey, PA: Information Science Reference, 2012), 391, https://doi.org/10.4018/978-1-4666-1821-3.ch022; Bruce Stoffel and Jim Cunningham, "Library Participation in Campus Web Portals: An Initial Survey," Reference Services Review 33, no. 2 (June 1, 2005): 145-46, https://doi.org/10.1108/00907320510597354.

${ }^{2}$ Mark Carden, "Library Portals and Enterprise Portals: Why Libraries Need to Be at the Centre of Enterprise Portal Projects," Information Services \& Use 24, no. 4 (2004): 172-73, https://doi.org/10.3233/ISU-2004-24402.

${ }^{3}$ Ilka Datig, "Walking in Your Users' Shoes: An Introduction to User Experience Research as a Tool for Developing User-Centered Libraries," College \& Undergraduate Libraries 22, nos. 3-4 (2015): 235-37,https://doi.org/10.1080/10691316.2015.1060143; Steven J. Bell, "Staying True to the Core: Designing the Future Academic Library Experience," portal: Libraries and the Academy 14, no. 3 (2014): 369-82.https://doi.org/10.1353/pla.2014.0021.

${ }^{4}$ Stoffel and Cunningham, “Library Participation in Campus Web Portals,” 145-46.

5 Tim McGeary, "MyLibrary: The Library's Response to the Campus Portal," Online Information Review 29, no. 4 (2005): 365-73, https://doi.org/10.1108/14684520510617811; Garrison, Prestamo, and Rodriguez, "Putting Library Discovery Where Users Are," 393-94. 